\title{
Arab Universities Towards the Social Responsibility
}

\author{
Prof. Randa M. Rizk
}

Professor of Educational Media, Cairo University

Universities Social Responsibility Advisor

\section{Abstract:}

he concept of social responsibility is no longer limited
to charitable and voluntary activity, but in fact it has
become a broader and more comprehensive concept that includes solutions to the economic, social and environmental problems of societies. Moreover, sustainable development cannot be achieved in isolation from the close relationship between higher education, its institutions and society. Universities are essential as a pillar of society, as they play a pivotal role in raising awareness of social responsibility among their students, faculty and other employees, in a way that causes them to act as social personalities who defend collective perspectives and do not choose to embrace individual thinking. Accordingly, the current research paper aims to provide a conceptual framework that clarifies the role of social responsibility of universities in sustainable development, dealing with the concept of social responsibility and its various aspects. The paper presents a number of recommendations that ensure that universities are strengthened in the social responsibility that is expected to achieve and support sustainable development efforts. The programs provided as an example to Future University in Egypt must also meet social needs, instead of expressing a purely economic perspective, they should contribute to the sustainable development of the context in which the university operates.

Keywords: Social responsibility, universities, institutions of higher education, sustainable development, social responsibility of the university, education, quality of education, voluntary commitment.

\section{Introduction}

Human societies are concerned in general with the social responsibility that is constantly being felt, as a result of the entitlement of the modern era, which requires a lot of efforts in order to control the evil, hotbeds of corruption, tension and work to provide a decent life for the citizen, and the cooperation of countries to solve global problems that one community cannot confront it on its own, and make a joint effort to reach appropriate solutions to it, such as environmental pollution and global warming, as well as child labor. 
The efforts of institutions are individually and do not concern with the importance of cooperation in the performance has become a major dilemma in light of the increasing dangers that threaten the collapse of society and its destabilization, and the ethical consequence of creating an appropriate environment as well as sustainable resources that depend on human rights principles that are universally established and that require participation of effective, and the exploitation of capital and human resources as well as material resources in order to provide sustainable community development and meet human needs and reduce the percentage of obstacles to development and the difficulties facing developing and developed societies.

It was still the universities - to that time - one of the most important platforms of civilization in all societies, and here it is the necessary departments as decent of the order to develop a sense of the extent of responsibility and community and pay workers to make them from just an idea to the behavior and the way the performance of the exercise of responsibility and community even take root in the minds of workers and students on both, even contribute to universities share a multitude towards the development of participatory task, that it is worth it to go on its impact and impact of the various areas of life, so enjoy the citizens of Arab - first - by the grace of the environment ( water, air and food ), and secondly by the grace of safety and stability, economic, and seen towards the development and progress, and thirdly to provide benefits necessary .. and it will not be achieved only by understanding the deep and tender and giving , and solidarity and participation, and initiatives praised, and investment exchange of interests as much as large .

If this responsibility, which must be include the actions of citizens and their minds must be revealed about perception and understanding even be able to renewal and repetition, development and improvement .

It is a responsibility that matches reality with all its components, and develops individuals' sense of their belonging to that country. The citizenship is the duty and the right of reaping individual from through society, which represents a crucible interact from which inputs to be transformed into an 
umbrella and the citizens fulfill their shades from all frameworks , classes , cultures and environments. Therefore, the university can from by giving responsibility to the community attention special stems from the message and the philosophy and vision of a clear subject for circulation when he found attention, whether it be that attention externally or internally .

This article is to review the definition of social responsibility , its importance, its origins and dimensions, and the issues that are related to it, the most important of which is finding the necessary means to achieve it as the presence of integration in the three sectors; private, governmental or public, as well as local community organizations, and also provides general guidance for the main principles that it includes, where exposure is It is for these means that planners, decision makers and administrators can incorporate the concept of community responsibility into strategies, mechanisms and practices related to institutions in general and educational in particular. If the starting points and principles are plenty in use, the responsibility then lies on the institutions in choosing what suits them, as well as the implementing them through cooperation with other partnerships and other. Some government institutions may use this guide in line with the tasks assigned to them, so that they can do so as they are not concerned with making changes in government duties, especially since all of these situations are voluntary and voluntary initiatives that are not considered for reasons that require changing the legal status of institutions by force.

Also from the work assigned to this article is to encourage universities to express their responsibility towards their communities, as well as their involvement in the diagnosis of the problems that face many sectors, and then arranging and organizing and activating plans and mechanisms that have common relationships to implement the goals and strategies able to achieve responsibility and community of through cooperation with all parties, and so with the knowledge expectations of the owners of institutions and the interests of society, civil and adherence to regulations and laws, and developing it with the trends established globally and locally.

\section{Preface}

In order that the responsibilities do not disappear and these efforts are in vain, it is necessary for the members of society to show solidarity to face these contemporary challenges. In order 
to do this, it had to define the roles of institutions and universities towards society, in order to improve the societal conditions of individuals economically and environmentally. The importance of the societal dimension has grown in all fields and administrative areas recently to link between the institutions and the community in which it operates, and this has required a highly efficient leadership that understands the challenges and importance of society, and the resulting decisions, procedures and actions that embody their social responsibility towards society and what they can achieve of positives for short and long tide.

In recent years, the topics on social responsibility have grown out of among the media, citizens, and private sectors, and we may be aware of the greater responsibility of that private sector. This is because we find that many of these institutions, including - for example - the Future University in Egypt - have designated specific departments concerned with social responsibility, including Hayat Foundation for Sustainable Development.

The principal aim of this paper is to identify the factors that define students' perceptions of university social responsibility (USR) in an Egyptian university, and analyse the impact of that view on their perceptions of satisfaction and quality of service. Particularly, it is hypothesized that the overall perception of university social responsibility has a positive effect on students' experiences of satisfaction, partially mediated by the assessment regarding the quality of university services. In doing that, a selfreport study was conducted with a total sample of 400 undergraduate students of Future University of Egypt. Structural equation modeling with PLS was used to test the students' overall perception of USR in order to achieve higher standards of quality of service and satisfaction. Results supported a structure of six factors explaining students' views regarding university social responsibility, of which only internal management affects the overall perception. Likewise, quality of service and satisfaction are strongly correlated among them. Implications of these findings for marketing in university settings are discussed.

However, the work of social responsibility has not been organized or arranged in a specific way, despite the presence of 
entities that started work in organizing it, and also at the international level, there is no system that follows social responsibility, as many countries are still preparing to prepare for that system. This confirms that the concepts of social responsibility are still hazy in Arab societies, where we see the educated citizen who is not aware of anything about social responsibility, so how about the illiterate or ordinary citizen?

The concept of social responsibility began to spread in the societies of Arab countries, around the year 2000 , because the role of civil societies did not increase and officials were convinced of the importance of the private sector in various civil efforts . It is here started this idea crystallized so because it is activity supportive of a later development sustainable and supportive of the efforts of the institutions of government .

In spite of this, it is not still the concepts of responsibility and community mixed within the sector a wide private in institutions and companies, also there is confusion between business charity and relationships public as well as between responsibility and community .

Egyptian universities are experiencing a process of world change which materializes into a new way of looking at the approach and purpose of education (Nuñez, Alonso, 2009). For this purpose, universities play a significant role in the next generations' ability to succeed and deal with globalization and economic growth, as well as to build a sustainable future for people all over the world (Setó-Pamiés et al., 2011).Consequently, education is seen as a key to improving quality of life, not just of individuals but also collectively for humankind (Galang, 2010). That is the reason why universities should approach and understand the consequences of the social changes that are shaping a new model of society. Particularly, universities need an interdisciplinary, open-minded approach able to cope with current needs and not locked up in traditional academic purposes (in both education and research) intended to meet a specific agenda (Gaete, 2012).

\section{The difference between social responsibility and charity}

From possible to determine the difference between responsibility and community and charity; where the charity is characterized by the nature of spontaneous and individual and 
personal, while including the responsibility of community and the existence of a plan and approach stems from the accounts of precise themes and priorities of her relationship needs necessary, and here is characterized by permanence .

The reasons for the emergence of responsibility and community :

If we try to track the beginning of the emergence of social responsibility, we find it begins through the major transcontinental companies, for two reasons: the first is the internal work environment, and the second is the presence of environmental risks in industry and petroleum companies, as these companies are keen to fight their employees and members of their families when they are exposed to risks in their work, the most important of which are insurance risks in general, health insurance in particular, and improving work environments.

The motives for social responsibility can be revealed as follows :

- All individuals bear societal responsibility towards the family, the soul, and society .

- The participation of individuals in charitable works is the basis for developing the economy and its independence .

- Governments must strive to encourage citizens to help themselves .

- Link between responsibility and community values and religious beliefs .

- Exchange of benefit between the institutions and the community of over spending on charitable work .

- Consideration of responsibility and community behavior to the commitment of positive institutions and companies towards society about through the development of human .

\section{The concept of social responsibility :}

It is difficult to develop a comprehensive definition that is often inclusive of a specific phenomenon or concept, especially if it comes to society and behavioral sciences, including the concept of social responsibility, as social responsibility has been defined from many different directions and angles. Drucker defined it in 
1977 as (an organized commitment of business towards the community in which it operates) as for Strier 1979 it indicated that it is a representation of society's expectations for business organizations 'initiatives in the areas of responsibility that business organizations bear towards society, and beyond the minimum level of submission to laws, and in a way that does not harm the business organization towards its main functions in order to obtain the appropriate return on its investments.

Bedeian - 1993 AD states that it is more appropriate to establish a definition of social responsibility by answering a question:

(What is the work that is considered a social official?) and here it proposes specific criteria for that, most notably:

- Organizations follow the following main criterion: (not to cause any harm, whatever the circumstances and reasons).

- Organizations bear legal accountability for any impact on society caused by their actions, while minimizing the lowest level of non-positive results of their actions.

- The welfare of society must be enhanced in the long term, and this makes organizations ready to pay for participation in the benefits of society, and these organizations must realize their continued dependence on the existence of a healthy and healthy society.

- As for the researchers (Pride and Ferrell 1997) they define social responsibility as being (the organization's commitment to amplifying the positive impact and limiting the negative impact, and from here it deals with the overall effects of all the organization's decisions within the community.

As for the draft of ISO 00 622, it defines social responsibility as the actions that the institution undertakes to be responsible for the effects of its societal and environmental activities, as those actions are consistent with sustainable development and the interests of society, and are also based on: (ethical behaviors, compliance with applicable laws, and the bodies that operate between governments, as they are incorporated into the institution's ongoing activities). 
The universality of the content of social responsibility made Carroll refer to it through its core in four main aspects: Legal, Economic, Philanthropy, and Ethical, where it made these four dimensions form a hierarchical pyramid to show the interconnectedness between them on the one hand, and on the other hand, any dimension is based on another is considered a reality, as business organizations are not expected to undertake any charitable initiatives unless they have come a long way in assuming moral and economic legal responsibilities towards the societies operating in them.

\section{Social responsibility and its common characteristics:}

Despite the definitions of social responsibility, they agree on common characteristics for them as follows:

- Its recognition of the principle of social responsibility and its subordination to institutions ( non- binding.)

- Integration of societal, economic and environmental policies in the daily management workers of the institution .

- Common characteristics of the concept of social responsibility

- Considering it as one of the main activities rooted in the strategic and administrative activities of the institution .

- Consider it as a participatory work undertaken by institutions to develop participatory capacity in development.

It carries out the social responsibility of various other institutions , regardless of the nature of their work .

\section{Principles of social responsibility :}

It is based on many of the principles, as focused on the nine principles of the basic ones :

- Protection of the environment (Environmental Restoration one of the dangers you face, especially with regard to pollution .

- It is based on ethics and values, as it is considered the safety valve for human and material investment and the direct relationship between them through the nature of activities that must take into account the value dimensions. 
- Accountability and accountability is done through the disclosure of accurate data and correct information based on the transparency of activities that have been implemented and that have not been implemented yet.

- Empowerment and strengthening of powers, and this is done through a balanced partnership between the private and public sectors as well as the audience of beneficiaries in order to achieve the interests that are exchanged in a manner that guarantees security and stability for the community.

- Financial Performance and Results: By reaching the best level of luxury resulting from retirement, salaries, provision, promotions, privileges and opportunities based on honest competition based on good performance, and preserves the development and progress necessary for the institution, and seeks towards self-growth and progress.

- "Workplace Standard" specifications and linking them with the human development resources management and improving the coaching staff according to the professional needs of the modern era, and providing a sound professional environment through which employees perform their work better, taking into account the necessary factors of lighting and quiet, and an open psychological environment.

- Collaborative Relationships that are built on honesty and justice with those involved in work, activities and assignments as well as the category that targets efforts.

- Community Involvement by intensifying communication between the various institutions of society, because the processes of communication and communication are characterized by a socially responsible sensitivity towards culture and the needs of that community, which finds the endeavor to provide the maximum benefits to citizens.

\section{Social responsibility and voluntary commitment}

- The voluntary commitment is considered one of the most prominent possible ways of practicing social responsibility, because some believe that compulsory volunteering is an alternative to instructions imposed on the behavior of institutions. On the other hand, others believe that the 
institution may claim volunteering, but the actual practices are inconsistent with the principles of social responsibilities, because they are formal, or they may be imaginary or even for the small goals that they can achieve. Whatever the voluntary commitment, nature, size and also its type, but it is not a substitute for this societal responsibility, but it is a limited part of the practice, hence it is clear that social responsibility is broader, more comprehensive and deeper, and is characterized by a systematic, permanent, plan and budget, through its achievement in society, and an important role in development. Social responsibility is not limited to specific contributions of volunteers in stable or emergency circumstances insofar as these are the main plans of social responsibility that take into account constructive, preventive and remedial measures.

\section{The public and private dimensions of social responsibility}

The state represents a major partner in all development operations, at a time when the business of corporations and companies has grown, and therefore it was necessary to have a partnership between the public sector and the private sector, due to the difficulty of the private sector working unilaterally in social responsibility without the need of the state, and the state is not able to play its roles without cooperation from the private and public sectors.

Through this we emphasize the role of the private sector, its importance and the role of the state, especially knowing that the economic system in Arab countries does not impose a tax on social responsibility, and from this the institutions should seek to develop targeted programs in partnership with government agencies.

Government agencies should also adopt social responsibility activities such as "education" and I consider that their curricula must include social responsibility, and that is a part that is currently present in their curricula, but it needs to be developed and specialization such as "national education" that works to bring up children to love their country, belong to and loyalty to their country and preserve State property, and this is part of the social responsibility entrusted to "education." 
Also, we see that the Ministry of Health possesses complementary activities in the sphere of social responsibility, for example: medical examination before marriage, and this is the tasks of social responsibility, where marriage between a female and a healthy male does not have genetic obstacles that have contributed to finding citizens in the community who are physically and mentally healthy, This is also the responsibility of the Ministry of Health, with social responsibility.

And it is not intended to enter sectors for the issues of community to abandon ministries for their tasks, but the purpose of this is to contribute to the development of sustainable. It is here must be on the sector, the private that means part of this responsibility and community .

And when we see some of the institutions that give their employees health insurance, give them remunerative salaries, and provide them with a suitable atmosphere for work, then this is considered a social responsibility. Also, when we look towards the work of many of the companies from through their products whether their products are harmful to the human and to the environment? That it is also considered the responsibility of social .

From here it becomes clear that what the private sector gives to society is less than expected, and does not rise to the return of these institutions and companies from its investments, and the reason for this is the lack of understanding of social responsibility - for example - we may see a certain company that grants material returns in different societal areas, given that this grant is a social responsibility we see that this is not true; the reason is that social responsibility contains programs, plans, programs, and plans. Not only the allocation of material returns, but also a significant difference. Hence, it is clear that what the private sector grants from this aspect is not hoped for, as there is disparity between each city and another, and also between institutions that grant societal assistance, and what is noticeable is our lack of a system of duty to the private sector towards social responsibility, and the absence of mandatory support, but perhaps the time comes when we will escalate a huge degree to the private sector, but this may become during the coming years, regardless of the matter towards concepts of social 
responsibility, or it may become actions in society, when the vision becomes clear, especially if we know that the government encourages any initiative from the private sectors to support its social responsibility .

Saudi Arabia is granted in the name of His Majesty King Abd له Al Saud. It also grants Jordan in the name of King Abdul-Thani to the institutions and companies that are concerned with social responsibility in accordance with the specific policies and specific criteria, in appreciation of the winning institutions and their contributions to the implementation of social responsibility activities .. It is worth mentioning the actions of His Highness Sheikh Mohammed bin Rashid Al Maktoum regarding preparing leaders to achieve responses Among the societal sectors and different segments, as well as the Emirates 'attempt to communicate in important projects, including: Sheikh Zayed Housing Project and the Charitable Marriage Fund Project, which indicates that social responsibility as a concept has begun to take root and that its importance has begun to emerge actually.

The implementation of measures for university social responsibility (USR) depicts an improvement in the management of the institutions themselves (Casani, Pérez, 2009), thus serving as a springboard for future professionals belonging to several sectors and areas of society, such as companies, governments or public administrations and organizations (Martí et al., 2008) that will lead to future changes worldwide. Literature suggests that business school emphasis on CSR can indeed make a difference in student attitudes. Therefore, universities are not only educational services providers, but also shapers of identity with major responsibilities to the nation and to the wider world (Sullivan, 2003). For this purpose, universities have a crucial role to play by incorporating social responsibility in the design of their curricula and researches, as well as into their mission, vision and corporate strategy (Muijen, 2004). The application of social responsibility in the field of higher education implies, among other issues, the identification of the university stakeholders and their perceptions of satisfaction and quality of service, the knowledge of their expectations and the establishment of means of dialogue with these groups. In this context, universities have to face this new mission, vision, and 
consequently design new institutional strategies of social responsibility, which include social responsibility in all academic areas as a way of obtaining a competitive advantage in this current context. Nevertheless, and in spite of the important social function of universities, there are still very few studies that include university stakeholders as the subject of research (Larrán et al., 2012).

\section{University social responsibility and the impact-based model}

Universities cannot stay out of line with current thinking on social responsibility and sustainable development, because it falls to universities to promote corporate social responsibility, scientific social responsibility and citizens' social responsibility in order to keep in mind the impact of higher education on knowledge, values and behaviour (Gasca, Olvera, 2011). First, the growing concern of nowadays universities to satisfy the needs of different stakeholders and to deal with a profound ecological and social commitment has imposed greater social responsibility on them (Kunstler, 2006). Second, universities have a crucial role to play in optimizing the way society is managed and attaining the objective of ensuring major improvements in people's lives. Third, universities are not only educational services providers (Sullivan, 2003) but also produce good citizens who are trained for both competency and character (Ehrlich, 2000; Wilhite, Silver, 2005). These are the reasons why more and more institutions of higher education are trying to foster and implement USR strategies in all university areas.

From this point of view, it is therefore sensible to define the concept of USR as a concept whereby a university integrates all of its functions and activities with the society needs through active engagement with its communities in an ethical and transparent manner which is aimed to meet all stakeholders' expectations (Esfijani et al., 2013:278). In other words, USR means to offer educational services with an ethical approach, to spread knowledge in a responsible way with good management and to respect and develop a sense of responsible citizenship by encouraging the students and the academic staff to promote sustainable development in their community as well as to try to adapt the higher education institutions' purposes, views and values. As with the corporate social responsibility, the USR 
concept has vague and imprecise definitions, because the areas of interest or attention are different depending on the institution which is seeking objectives. Furthermore, there are different names for the concept, which are presented as separate although they should really be under the USR umbrella concept, such as sustainable development, development cooperation (Ministry of Education, 2011), ethics (Dellasportas, 2006; Lutar, Karri, 2005) or third mission (Casani, Pérez, 2009). Most of the alternative concepts are focused on environmental and social areas the term.

Table 1 Impact-based model of USR

\begin{tabular}{|c|c|c|}
\hline & Definition & Results \\
\hline Educational & $\begin{array}{l}\text { Refer to responsible processes of } \\
\text { teaching, learning and values education }\end{array}$ & $\begin{array}{l}\text { Responsible Civic and } \\
\text { Professional Education }\end{array}$ \\
\hline Cognitive & $\begin{array}{l}\text { Refer to ethical guidelines, theoretical } \\
\text { approaches, lines of research and } \\
\text { production and divulgation of knowledge }\end{array}$ & $\begin{array}{l}\text { Social Management of } \\
\text { Knowledge }\end{array}$ \\
\hline Organizational & $\begin{array}{c}\text { Relative to members of the academic } \\
\text { institution through the organizational } \\
\text { design of the university, its plans and } \\
\text { strategies }\end{array}$ & Responsible Campus \\
\hline Social & $\begin{array}{l}\text { Links between the university and external } \\
\text { stakeholders and their participation in } \\
\text { the political, social, economic and cultural } \\
\text { development of society }\end{array}$ & Social Collaboration \\
\hline
\end{tabular}

(Ministry of Education 2011) and hinder the understanding of Source: Adapted from Gaete (2012); Vallaeys et al., (2009)

Social responsibility between charitable work and systematic planning

The phrase "corporate social responsibility" began to sound our ears and aspirations in the press and the print media, which have become widely available in recent years. But the features of that concept did not take shape clearly, especially for institutions that have not succeeded until now to launch towards international and regional markets. In the best conditions, we find that most societal initiatives still remain within the limits of expressing the good intentions of institutions towards the society in which they conduct their activities. 
And if we look at the aspects of society for us as coherent Arabs, we find that we agree with each other on many issues of society even before the advent of Islam, and when Islam came, these bonds were established between Muslims, and there are verses from the Qur'an and the hadiths of the Prophet, which indicate the charity of compassion for the poor and relatives and relief of the dear. The most prominent aspect of this is the section on Zakat, which is at the heart of social solidarity, where the private sector is paid to give Zakat according to the type of product or what the person has in this aspect.

Perhaps it comes to mind that the presence of charitable projects for the needy, blankets and school bags is a societal responsibility, but it is an approach that hurts a lot, because societies increase misery and the rich increase the superiority and supremacy to perform its mission in the best way.

Therefore, we must know that social responsibility was never limited to spending, but spending is a way to reach specific things within the framework of social responsibility that includes sustainable development patterns. Also, we must be aware that social responsibility in its broadest sense does not represent donation from the viewpoint of private sectors, as private sectors adhere to institutional work within companies, starting with a commitment to employees, society and the environment in general.

And add the required here in this area is the development of plans and programs, as the main goal that we seek to achieve is the access to all institutions, so that we provide within those institutions and corporations - including universities departments related to social responsibility work, also the educational institutions must focus on the strategies concerned with social responsibility, as well as a separate budget should be allocated as an obligation towards society .. Whenever the institution or company appoints employees and sets a budget and programs, this is called sustainable human development that we must strive to achieve ..

Also, through that, we must talk about voluntary charitable work that cares for the needy, the poor and the needy in isolation from the social responsibility that is concerned with the 
development of society and based on strategic plans and important programs.

When regional, national and international economic, commercial and financial institutions were formed as a major source of wealth as well as an effective tool for providing employment and modernization opportunities in any society, no one expected those institutions to be concerned with charitable work, because they are based on their ability to make profit for their shareholders. But of course, the responsibility of companies and institutions should not stop there, but also moral, social and environmental responsibilities.

The concept of social responsibility is repeated in the words of businessmen, and this is not translated into reality except through unilateral initiatives such as donations in times of crises .. Hence many questions arise that require a definite answer, including: how these efforts are organized and how they are mobilized in a manner that complements the plans developmental and changes the conditions of poverty? How can these factories contribute to serving the surrounding communities beyond what is said in advertising and propaganda? Can businessmen associations serve citizens in the interests of the members working for them so that the partnership can be achieved in its meaning in reality?

The corporate social responsibility of corporations and companies has now become necessary and appropriate in companies that truly value the meanings involved in practices of such social responsibility. Following the example of what is happening in the West, where corporate social responsibility has deep roots, and there are many companies around the world that have exceeded the scope of exercising those responsibilities through charitable companies and institutions, and have introduced them into the depth of their practical activities strategies and incorporated them into administrative practices.

The reason for this major shift in the western world towards the inclusion of social responsibility for institutions and companies within their basic strategies, mainly due to issues related to promoting activities for the activities of institutions in general. In addition, there is a belief that institutions can improve 
their contribution to reach a public interest by focusing on key elements of social responsibility.

These Arab countries generally suffer from a lack of a culture of social responsibility or awareness of its concept and confuse it with charitable work even with the institutions themselves. Social responsibility has broad meanings linked to adherence to laws and regulations in place and environmental and health aspects, as well as taking into account human rights. Especially the rights of workers and the development of local communities and the commitment to fair competition and after them for consumer satisfaction and monopoly, social responsibility remains occupied the stage of growth and when it reaches the global average, but most of them are separate efforts approaching charity more development because they are limited to feeding the poor and providing clothes and services without addressing development projects to change the standard of living the poor are radically and sustainable despite the activities of associations associated with businesses that are not concerned with small and medium-sized enterprises.

Social responsibility is not limited to setting up development or charitable projects, but it includes training components, as industrial institutions are assigned a role towards developing and developing the performance of their employees through training, in addition to their responsibility to participate with educational institutions - especially universities - by giving opportunities to learners and students for education and training inside the factories. This aspect is largely neglected in social responsibility.

The introduction of social responsibility for companies and institutions requires the presence of strategic plans, where more depth and understanding of that responsibility is required, and the content it contains. There are a host of factors to consider, as corporate social responsibility has made it a strategic concept that needs more attention to local social and political risks. It should be noted that there is no standard size commensurate with all forms of corporate social responsibility.

\section{Social responsibility and its position in university jobs :}

Universities preferred significantly in the provision of qualified scientific and specialized to the needs of the community and secure; and that because responsibility and community in the universities face a lot of obstacles that are most notably. 


\section{The university in light of the values concerned with community service}

The university is not now just a factory to provide scientific degrees or graduate young people who have successfully completed educational curricula, and is no longer a repository of laboratories and knowledge to conduct scientific research, but the concept of the university has evolved to become concerned with the goals and many purposes that focus its efforts in the society in which it was established, it is born from the womb of that community and devotes its work to develop it on a range of different axes and levels.

First: the growth of knowledge - or the knowledge explosion that the university contributes to its creation, and the methods and tools for obtaining that knowledge, as well as storing, analyzing and retrieving it, hence the efficiency of the university and its strength and the level of students have also become of great importance, as it contributes to determining the level of social progress and its economic parts Social and cultural.

Second: Technical progress: This is what imposed on universities specific directions, as there is no longer an opportunity for the university to be isolated from that development and progress, and it has become one of its responsibilities to advance society and enter it into the era of scientific technology, observation and contribution to technological development as well.

Third: Development: This establishes the link between society and the university, and perhaps the role of higher education in contributing to development plans is one of the main reasons behind the development plans' backwardness, because the university pays for the development of scientific and applied research, as it links this research to practical reality, as it studies problems of agriculture, industry, production sectors, various service sectors, and work obstacles. It also strives to prepare the human competencies and frameworks needed by society in various activities, and is provided with modern knowledge and diverse experiences, hence providing it to society.

\section{Universities and their social responsibility :}

From the beginning, universities considered the concept of social responsibility as an activity that universities perform in order to serve society, although other or some institutions are what distinguish that difference from the university, where the 
type of services is determined by the institution, and also in light of this the universities differ - in social responsibility - From other companies, and it is very unfortunate that educational institutions and universities viewed this responsibility as an investment for a misunderstanding that was addressed by material purpose, although the investment of this social responsibility does not have a positive impact on educational institutions only, but on the educational sectors National full when it sets goals and emerge through the plans and priorities.

Physical difficulties have played a major role in the difficulties facing any activities related to social responsibility within companies or educational institutions, as they became concerned with this only if they realized the financial return of universities, rather than the other way around, or that there are parties abroad that finance these activities, and in most of the time, there will be keenness from universities not to bear any financial expenses, so that there are educational institutions that are free of any participation in community activities, and therefore they do not have a decision regarding part of this social responsibility, as if their energies and human facilities were found only for university education, and even programs the continuing educational that is supposed to provide community services related to the university's specialization and capabilities.

\section{University social responsibility and continuing education:}

The goals of continuing education have become only financial gain, for example, we find that a local university has offered thirteen courses at the same time, and four have been canceled, as a result of insufficient trainees, or in other words due to material losses, and with a simpler estimate does not occur dealing with those activities As one package, although the measurement is not valid from a physical perspective, and in return it is not possible to accept reaching that limit in measuring any activities only from a physical side.

\section{Responsibility and community hubs that can universities be practiced:}

The axes of social responsibility include a number of areas that are able to meet the needs of citizens, as they do not leave one side or one of the areas of society except that I have addressed it through a holistic view and integration between the 
various influences in building society in a way that emphasizes its security, stability and development, and among the most important of these axes of the social responsibility in which universities play an important role

\section{The foundations of the universities' upgrading with social responsibility :}

Upgrading societal responsibility at the university needs a set of elements that must be taken into consideration. These elements are:

- There are specific needs for society and the labor market and work to meet these needs.

- The existence of a study of the abilities and desires of the students " students " and work to provide as consistent with the frameworks of public society and orientations .

- Seize the opportunity that ensure the achievement of the visions that seek from which the philosophy of universities towards responsibility and community .

- The existence of a plan entrusted to social responsibility as a main component of the strategic plan that was announced.

- Declaration of results achieved by the university in the areas of social responsibility and those that seek to achieve as an important trend for sustainable development.

Implementing social responsibility and university gains, including :

- Some may ask : What is the university's return on applying social responsibility?

- It is not easy to determine the answer to that question in a specific angle, considering the university an umbrella that covers with its interests the different directions of society, but we can mention some of the university's gains, such as:

- Enhancing the university's position and reputation in the community and a sense of the university's general goals and mission.

- A long-term return on community investment has been achieved.

- Providing opportunities to test and innovate new product services. 
- Developing and training the skills of residents locally to have tributaries they need to enter the labor market.

- Increasing community and customer affiliation with it, as well as enhancing the team spirit of the company's team?

- Achieving social responsibility for positive impacts on students and their academic practices, the most important of which are:

\section{The importance of participation that achieved by} universities :

The university achieves cultural, educational, productive, and services with other institutions in the community, through which it can integrate with community activities, as it is strengthened in this importance for the work of the university through:

- Activate a significant impact on society and gain experience in its service.

- Availability and investment of living resources and the creation of new communication channels.

- Specialization of the programs and experiences the university needs in dealing with special needs and managing social institutions.

- Establishing long-term relationships with the community as a major pillar of the university.

Overall, we can say that providing distinguished services to the community has a positive reflection on the progress of the university and its development, whether through its impact on local communities or by the impact of these societies on the university, and from here the message of universities turns into causes and results at the same time.

\section{The responsibility of the community in the universities and their needs :}

It needs to achieve responsibility and community to a number of actions that can be summarized as follows :

First: Choosing a methodology :

Methodology : documented salary planning that shows us how to achieve social responsibility . 
Second: Preparing social responsibility management systems :

The systems of social responsibility are in a necessary need for permanent improvement and development, and there are proposed systems for building a permanent improvement system for the work of social responsibility characterized by its reliance on planning goals, clarity, partnership and evaluation of performance with the other, based on clear policies towards social responsibility as follows:

Third:Developing the university's internal and external communication plans :

Identify the necessary resources : human or non- human .

- Limitation of liability .

- Defining the message and its content .

- Define the required activities according to a specific schedule .

- Determine implementation responsibilities .

- Determine the measurement index .

- Correction and evaluation procedures .

\section{Defining university visions of social responsibilities}

It is here must determine the vision of the university responsibility and community of through nature

\section{University social responsibility message}

No need to start a message of responsibility and community universities according to :

Strategic directions for building strategic plans in universities

There are four orientations of the strategy Chairperson proposed to establish responsibility and community in universities

\section{Setting community priorities}

With the identification and selection of community projects and their activities, attention should be paid to a number of considerations that must be taken based on harmonious objective facts and axioms that reflect the importance of those projects that are proposed and their feasibility for implementation by universities, namely: 
The success of universities and their constituents in achieving social responsibility :

- If these ingredients behind the success of universities in achieving responsibility and community does not come only with the province of universities on the basic towards workers and individuals within the community, as well as respect to this from the consequences of legal , economic and ethical towards the human and the environment together, and form the following illustrates these bases and ingredients .

- Laying down legislations, laws and regulations to activate the partnership between the three sectors : the governmental and private sectors .

- Contributing to the creation of a body responsible for community responsibility at the national level

- Provide incentives and encouraging facilities to fulfill the role of social responsibility

- Provide the potential for a crisis in order to attract sectors own .

- Provide accurate indicators with clear criteria to determine the effects and results of university programs for social responsibility

- Universities start creating a concept of sustainable development in all their businesses .

- Activating the role of the university's social responsibility by building special cadres for that

- Contributing to the development of civil society institutions and charitable works so that they are capable, competent and efficient in achieving the desired result.

- Aiming to increase awareness of the culture of grant and institutional giving at the same level, as well as the culture of giving.

- Aiming to correct misconceptions that the needy can deal with their needs only through charities or government agencies.

Social responsibility in universities and the starting points for their activation :

- Work on the existence of the budgets of specific and are specifically to support programs that are the responsibility of the community . 
- Work to establish priorities in order to manage and support program operations with separate budgets away from the university .

- Support and encourage volunteer staff as well as their involvement in those associations and civil or within universities, or making it one of the most important strategies for universities .

It is through it is clear that the activation of responsibility and community in the university depends on taking a series of measures, procedures and activities that ensure the success of universities in achieving the responsibility of the community, with a bearing in mind the upbringing of awareness of the relevant even aware of communities - from through this awareness - which is able to achieve management of self that Among the most important :

\section{An example of an executive activity :}

Actions to achieve the activity :

Trying to find those sponsoring employment, it is best to search for which has a strong reputation .

- Inviting university graduates who are missing a job by reviewing the official of employment files and filling out resume forms for that.

- Specifying specific parties through which to provide job opportunities for different specialties.

- Correspondence with these authorities about the existence of goals expected from the day of employment.

- Prepare specific forms that include identifying opportunities for employment.

- Determine the location and date of employment on the occasion through newspapers and other addresses.

- Inviting those who wish and those who confirmed their participation through a special program for graduates and institutions, as well as enhancing dialogue between them, as well as building common relations.

- Keep follow-ups open, and specify the number of those who obtained the jobs.

- Evaluating the activities of the employment day as a feedback for this approach. 
- Establishing data bases for universities that include employers and university graduates, benefiting from these experiences, and disseminating them to other agencies or other appointments.

\section{Quality assurance mechanisms in higher education}

When quality is evaluated based on a predetermined model that is not designed to take into account the specific context, the impact on quality may well be negative rather than positive (regardless of how perfect the model in question may seem). Quality is a social construct and as such it requires reflection, dialogue and collective effort (Días Sobrinho, 2007), all of which must take place in the specific context in which an HEI operates. Clearly what works for one country will not necessarily yield positive results in another.

International trends indicate that accreditation of institutions and academic programmes is currently the most widely used quality assurance mechanism. Accreditation usually involves two basic processes: institutional accreditation by national and/or regional agencies, and evaluation of programmes, generally by professional associations.

We must always bear in mind that one of the main reasons for promoting accreditation is to ensure that HEIs pursue, improve and uphold their own standards, in accordance with the state of knowledge and their social responsibility. If accreditation fails to accomplish this, it cannot ensure public trust in the quality of institutions and programmes and the process becomes a pointless exercise.

It is therefore important that quality assurance mechanisms such as accreditation are constructed based on principles of good practice. When such mechanisms are being defined, every dimension of an institution should be questioned, with the extensive participation of all relevant actors in the design of processes.

Quality assurance mechanisms must be based on criteria that take account of relevance, democratisation, social equity, local and regional development, and the creation of public spaces for discussion. Evaluation should not focus exclusively on quantifiable products and results. Other aspects that should be 
looked at are educational processes and qualitative approaches; understanding of causes, conditions for production and contexts; and economic, social, cultural and political impacts and effects. Also, quality assurance mechanisms should place greater emphasis on assessment of solidarity and intra- and interinstitutional cooperation than on competitiveness, and should include an examination of performance with respect to social responsibility and public commitments.

Suggested general frameworks to interfere in inspiring and achieving a culture of social responsibility for universities :

The achievement of the responsibilities of community in the university requires the adoption of specific procedures to consolidate their practices towards that dimension is important, and perhaps the most important of those actions that constitute a basis solid foundation towards the start of universities in framing this matter and rooting it in the hearts of students and staff, and there is a framework of a proposal for intervention in the inspired culture of responsibility and community universities that can be achieved through the following :

- Include responsibility and community plans strategy for universities and to identify the area of intervention , according to the dimensions of the three are : the dimension of social, economic, and environmental .

- Offering compulsory courses at the university concerned with social responsibility, so that it includes a comprehensive briefing on this topic through two angles: the first is a theoretical angle, and the second is an applied field. This situation is considered an alternative to the decisions of community service, which has become a limited part of social responsibility.

- The university appoints a coordinator for the decisions of social responsibility in order to cover the theoretical dimension and follow-up activities and field work for students, which must be documented through a database through which it is easy to deal in different situations. Also, a guide has been issued for activities that can be replaced with community services.

- Inclusion of concepts of social responsibility, its dimensions and principles in the study curricula, with a focus on activating the values of altruism and voluntary work and engaging in community issues . 
- Increasing interest in conducting research and studies related to societal responsibilities, with the aim of identifying and avoiding weaknesses and enhancing strengths in the relevant policies.

- Dissemination of cultures and principles of social responsibility for companies and institutions in general and for universities in particular among their employees through organized training or through non-systematic programs, events and activities, and perhaps also the issuance of bulletins and the allocation of websites in this necessary need.

- Forming a task force tasked with achieving social responsibility across universities and spreading the idea to institutions.

- Deepening the practice of social responsibility professionally as this has positive effects on various other aspects, especially administrative.

- Defining general frameworks for the employees' contribution to achieving their social responsibility by volunteering for work days in other institutions or carrying out specific activities and tasks that support that aspect, in addition to specifying a specific financial contribution $(1 \%)$ of the month's salary) and is calculated at a rate of once per semester with the aim of achieving this the purpose.

- Activating the role of universities in civil society services by holding specialized training courses in a variety of fields, including community needs in the areas of implementation, planning and evaluation.

- Holding workshops, conferences, meetings and seminars that support the local community and advocate for its issues in all areas, such as women's workers rights, combating domestic violence, citizenship and legal culture .

- Activating the culture of innovation creativity and advertising for competitions, research, scientific or discoveries and inventions that serve the society and its development.

- Provide guidance and advice for the implementation of the work programs of the various community institutions .

- Contributing to the development and support of the higher educational and school system .

- Contribute to the development of programs for the care of people with needs special.

- Activating the role of counseling academic in the promotion of superiority of one hand, and stand at the reasons for failure to 
school and work to avoid them to reduce the wastage of economic, social and educational .

- Achieve higher levels of job satisfaction and public safety requirements .

- Providing the appropriate field for professionals and educators in the local community in order to benefit from scientific developments, given that universities are the incubator for lifelong learning.

- Enhancing scientific competencies financially and morally to achieve high levels of advancement and progress, in a manner that reduces brain drain.

- Building a financial fund through contributions and half the value of the installments paid by students, and searching for donors and partners to cover social responsibility programs, events and activities.

- When choosing the different activities and events, the involvement of workers and students in determining them as priorities is necessary, and it is necessary to announce them within a period of not less than three months before starting to implement them.

- Endowment when economically necessary and take plans to fight poverty through local communities and students.

- Participate in building a common trend among citizens by preserving their immortal legacies in all their forms and colors, as well as caring for the preservation of treasures and monuments that have been historically immortalized.

\section{Conclusion}

Few what seizes the subject of worthy importance and consideration as much as captured by the responsibility of the community, in application theory, that by virtue of the growing interest in the actual importance of the involvement of companies and institutions and especially the university in issues of community highlights, as well as to contribute as much as large very of interaction, which helps to reduce the dangers of the environment, and others of the dangers - to , for example , but not limited to - as well as issues of society and other instead of switching to the hotbeds of crisis and tension .

It is through that must be on an industrial decision in society imitators in the equation of the Trinity, which consists of sectors , public sectors and civil sectors own to fulfill their obligations, so that if what has been overlooked one of these sectors 
participation were the results cut off by virtue of the gap that leaves each of the sector of them .

In conclusion, I thank you very much and abundant gratitude to Hayah Foundation for Sustainable Development, and Future University of Egypt and the efforts of many in providing an environment suitable provided an opportunity good to enrich it oriented and framed .

\section{References}

- Angell, R. J., Heffernan, T. W., Megicks, P. (2008), "Service quality in postgraduate education", Quality Assurance in Education, Vol. 16, No. 3, pp. 236-254.

- Argandoña, A. (2012), Otra definición de responsabilidad social. Cátedra "La Caixa" de Responsabilidad Social de la empresa y gobierno corporativo. IESE Business School. Universidad de Navarra.

- Barclay, D., Higgins, C., Thompson, R. (1995), "The partial least squares (PLS) approach to causal modeling: Personal computer adoption and use as an illustration", Technology Studies, Vol. 2, No. 2, pp. 285-309.

- Barnes, B. R. (2007), "Analysing service quality: the case of postgraduate Chinese students", Total Quality Management \& Business Excellence, Vol. 18, No. 3, pp. 313-331.

- Bitner, M.J. (1990), "Evaluating service encounters: the effects of physical surroundings and employee responses", Journal of Marketing, Vol. 54, No. 2, pp. 69-82.

- Bolton, R.N., Drew, J.H. (1991), "A multistage model of customers' assessments of service quality and value", Journal of Consumer Research, Vol. 17, No. 4, pp. 375-384.

- Burcea, M., Marinescu, P. (2011), “Students' perceptions on corporate social responsibility at the academic level. Case study: The faculty of administration and business", University of Bucharest. Amfiteatru Economic, Vol. 13, No. 29, pp. 207-220.

- Carrilat, F.A., Jaramillo, F., Mulki, J.P. (2009), "Examining the impact of service quality: a meta-analysis of empirical evidence", Journal of Marketing Theory and Practice, Vol. 17, No. 29, pp. 95110.

- Casani, F., Pérez, C. (2009), "La responsabilidad social en las universidades públicas españolas: Vectores de cambio en la gobernanza", Investigaciones de Economía de la Educación, Vol. 4, pp. 127-137. 
- Ceulemans, K., De Prins, M., Cappuyns, V., De Coninck, W. (2011), "Integration of sustainable development in higher education's curricula of applied economics: Large-scale assessments, integration strategies and barriers", Journal of Management and Organization, Vol. 17, No. 5, pp. 621-640.

- Chia, J., Hsu, J. Hsu, C.M. (2008), "The relationships between service quality and customer satisfaction in a leading Chinese web 2.0 company", The Business Review, Cambridge, Vol. 11, No. 1, pp. 84-90.

- Chin, W.W. (1998), "The partial least squares approach for structural equation modeling", in Marcoulides, G.A. (Ed.), Modern methods for business research, Lawrence Erlbaum Associates, Mahwah, NJ, pp. 295-336.

- Chin, W.W. (1998a), "Issues and opinion on structural equation modeling", MIS Quartely, Vol. 22, No. 1, pp. 7-16.

- Christensen, L.J., Peirce, E., Hartman, L.P., Hoffman, W.M., Carrier, J. (2007), "Ethics, CSR, and sustainability education in the financial times top 50 global business schools: Baseline data and future research directions", Journal of Business Ethics Education, Vol. 73, No. 4, pp. 347-368.

- Correia, S. M., Miranda, F. J. (2012), "DUAQUAL: The quality perceived by teachers and students in university management", Cuadernos de Gestión, Vol. 12, No. 1, pp. 107-122.

- Dellaportas, S. (2006), "Making a difference with a discrete course on accounting ethics", Journal of Business Ethics, Vol. 65, No. 4, pp. 391-404.

- Ehrlich, T. (2000). Civic Responsibility and Higher Education, Westport: The American Council on Education and the Oryx Press.

- Elliott, K. M., Healy, M. A. (2001), "Key factors influencing student satisfaction related to recruitment and retention", Journal of marketing for higher education, Vol. 10, No. 4, pp. 1-11. 